DOI: 10.14526/2070-4798-2020-15-1-135-141

\title{
Physical culture teacher's professional activity effectiveness monitoring
}

\author{
Artem F. Filipov*, Raziya F. Akhtarieva \\ Yelabuga Institute (branch) Kazan (Volga) Federal University \\ Yelabuga, Russia \\ ORCID: oooo-ooo2-3459-7971, filipovartemf@gmail.com* \\ ORCID: oooo-ooo2-7423-7671,raziya-a@yandex.ru
}

\begin{abstract}
The article is about the approach to estimating the effectiveness of professional activity of a teacher in terms of native education paradigm change in the existing standards of education. The aim of the research: to reveal and test the mechanisms and ways of estimating professional activity of a teacher on the basis of secondary schools, taking into account modern demands claimed on educational results. Research methods. The research methods included information sources analysis and summarizing, questionnaire survey and the methods of mathematical statistics. Student t-test was also used. Results. We revealed the degree of the educational results achievement according to Federal State Educational Standards and the degree of labor activity realization by teachers according to professional standard of a teacher. We revealed correlational connections between the components and estimation criteria on the basis of the educational standards demands. We formulated possible reasons of difficulties during a teacher's professional activity realization. We present general recommendations concerning the problem zones elimination, revealed in this research work, and concerning further research works. Conchsion. We made some conclusions concerning creation and testing the methodology of a teacher's professional activity estimation. We present general results of the methodology use and the recommendations concerning its further use.

Keywords: effectiveness of educational activity organization, federal state educational standard, professional standard of a teacher, personal and metasubjective educational results, labor actions of a teacher, correlational analysis, educational results specification.
\end{abstract}

For citation: Artem F. Filipov*, Raziya F. Akhtarieva. Physical culture teacher's professional activity effectiveness monitoring. Russian Journal of Physical Education and Sport. 2020; 15(1): 110-114. DOI: 10.14526/2070-4798-2020-15-1-135-141

\section{INTRODUCTION}

Nowadays the quality of a teacher's professional activity estimation is mainly determined by such indices, as the results of Unified National Exam (UNE), students' results at the olympiads and other results. The estimation is also held during teachers' accreditation in order to define his or her qualification category. However, with the pedagogical paradigm of education renewal the demands claimed on a teacher's professional activity had also changed. It leads to some contradiction: a teacher's work, which has to correspond with the demands of modern educational standards. It is estimated using outof-date approaches and mechanisms of evaluation. At the same time, if subject educational results are traditionally achieved at a high level, then personal and metasubjective educational results achievement by the pupils is difficult.

The problem of effectiveness evaluation of physical culture teacher's work is in evaluation criteria and parameters, forms and methods determination, their introduction into practice, providing reasonable use of staff, administrative and methodical solutions and stimulating professional development of a teacher.

The problem of evaluation criteria and indices substantiation is presented in some works of native scientists: B.G. Ananev, E.M. Ivanova, E.A. Klimov, A.G. Kovalev, V.N. Myasishchev, I.M. Paley, K.K. Platonov, Yu.P. Povarenkov, V.D. Shardrikov and others. The questions of choosing the parameters of pedagogical activity effectiveness evaluation are considered in the works of I.A. Zimnyaya, N.V. Klyueva, L.S. Kolesnikov, V.A. Krutestkiy, N.V. Kuzmina, A.K. Markova, L.M. 
Mitina, Yu.A. Samarin and others $[1 ; 2 ; 3 ; 4 ; 5 ; 6]$.

The aim of the research: to reveal and test the mechanisms and ways of estimating professional activity of a teacher on the basis of secondary schools, taking into account modern demands claimed on educational results.

\section{MATERIALS AND METHODS}

Theoretical base of the methodology creation of physical culture teacher's professional activity effectiveness evaluation is the following: system-activity based, activity based-personal and competence based approaches to educational practice effectiveness estimation.

During the estimation we used such research methods as a questionnaire survey, comparative analysis, methods of mathematical statistics.

A questionnaire survey meant that during the process of effectiveness evaluation teachers were offered 2 lists of criteria according to the existing educational standards.

The diagnostics criteria of the professional activity effective evaluation were 11 personal (P.1 P.11) and 12 metasubjective (M.1 - M.12) educational results according to Federal State Educational Standards of the main general education (MGE) with the opportunity to estimate according to 5-point scale [7-12].

The criteria of a teacher's professional activity effectiveness estimation procedural component diagnostics are the labor activities of "Teacher" professional standard: 10 labor actions of such labor function, as "General pedagogical function. Teaching" (T.1 - T.10), 11 labor actions of labor function "Upbringing activity" (U.1 - U.11), 11 labor actions of labor function "Developing activity" (D.1 - D.11), 7 labor actions of labor function "Pedagogical activity directed toward general and secondary education programs realization" (PR.1 - PR.7), also with the opportunity to estimate according to 5-point scale [8].

The research was held in 84 teachers on the basis of municipal budgetary educational establishment "Secondary school № 1", municipal budgetary educational establishment "Secondary school № 8”, municipal budgetary educational establishment "Secondary school № 9", municipal budgetary educational establishment "Secondary school № 10" in Yelabuga region of the Republic of Tatarstan.

\section{RESULTS AND DISCUSSION}

During the questionnaire survey some teachers failed to understand the formulation of professional activity effectiveness evaluation criteria. They were taken without changes from the text of the official educational standards.

Defining qualitative degree of educational results achievement, we came to the conclusion that a minimal necessary level of each effectiveness index is $75 \%$ from the maximal possible mark. Thus, minimal necessary level of professional activity effectiveness is achieved if each criterion had 4 points.

As professional pedagogical activity is directed toward the definite results achievement during teaching and upbringing process, the effectiveness is estimated, first of all, according to educational results. It is common knowledge that each teacher doesn't have to achieve the full volume of each educational result according to FSES MGE, as these results achievement is realized through mutual activity of the whole educational organization teachers. That is why the effectiveness of teachers' professional activity estimation is realized, first of all, as a result of the selective average educational results comparison and labor functions according to the whole sampling with the necessary level.

The results of the questionnaire survey went through the initial statistical handling by means of calculating the means of central tendency and the measures of data scattering. Selective average educational results and labor actions of a teacher according to the whole sampling in general are presented in a form of radar charts (picture 1 ). 

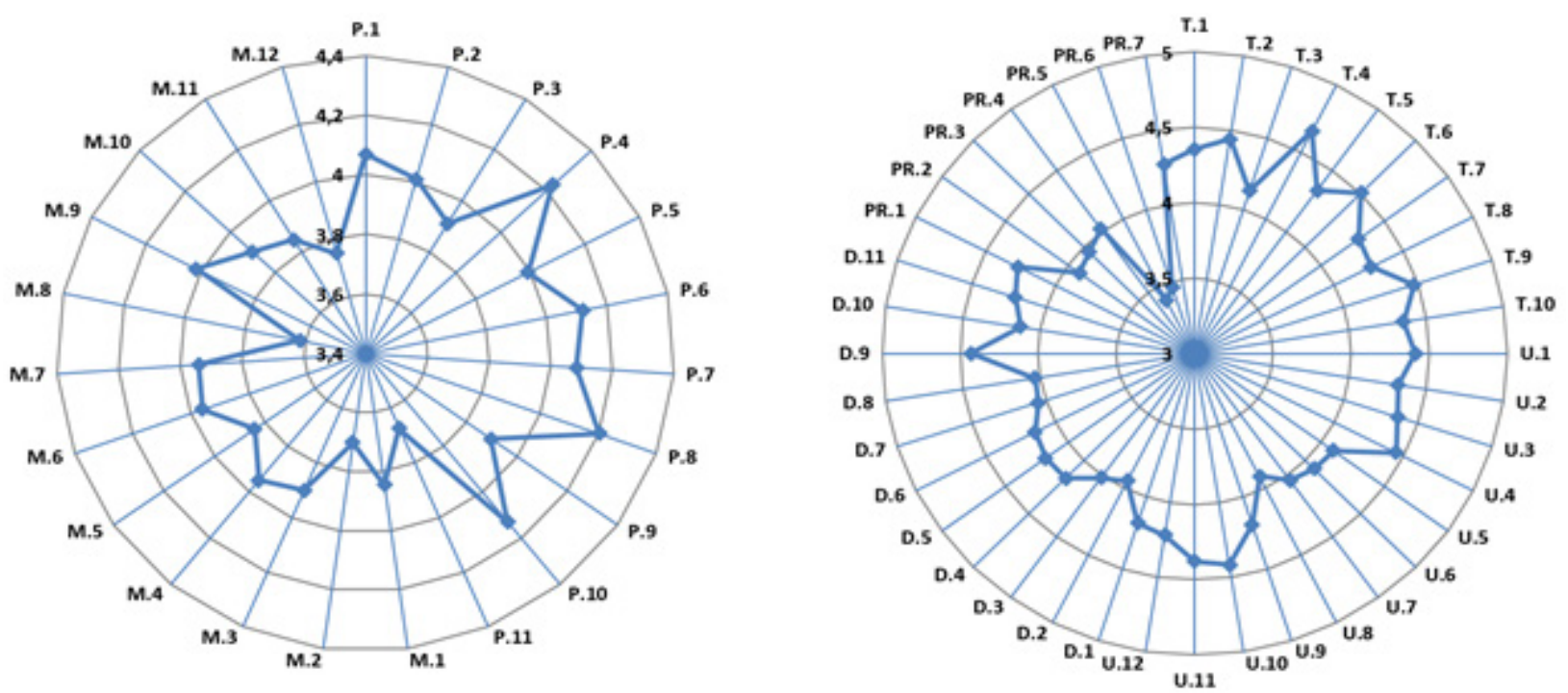

Fig. 1. Mean values of the degree of educational results achievement (on the left) and a teacher's labor actions realization (on the right)

As the selective mean value went through statistical discrepancy during empirical results collection, we checked statistical validity of the differences from the necessary level with the help of Student t-test.

During the check (at the significance level $\mathrm{p}<0,05)$ it was stated that insufficient degree is achieved by 8 educational results (1 personal and 7 metasubjective results):

P.11 - aesthetic consciousness development through mastering art heritage of the Russia and the World nations, creative activity of aesthetic character;

M.1 - the ability to define independently the aims of own education, set and formulate new objectives in education and cognitive activity, develop motives and interests of own cognitive activity;

M.2 - the ability to plan independently the ways of achieving aims, including alternative ones, choose the most effective ways of educational and cognitive problems solution;

M.3 - the ability to correlate own actions with the planned results, realize control over own activity during the results achievement, define the ways of actions in accordance with the changing situation;

M.5 - mastering the basis of self-control, self-estimation, decisions making and choice realization in educational and cognitive activity;

M.8 - notional reading;
M.11 - competence formation and development in the sphere of informationcommunicative technologies use; motivation development to the culture of active dictionaries and other searching systems use;

M.12 - ecological thinking formation and development, the ability to use it in cognitive, communicative, social practice and professional orientation.

These results prove that students' regulative universal educational actions are not sufficiently developing during professional pedagogical activity.

It was also revealed that (at the level of significance $\mathrm{p}<0,05)$ only 2 labor actions are not sufficiently realized:

PR.5 - special language programs use (including Russian language as foreign), the programs of language culture improvement and the skills of multicultural communication development;

PR.6 - cooperative (with students) use of foreign sources of information, instruments of translation and pronunciation.

Moreover, with the help of statistical analysis methods we defined how many teachers achieve validly high personal and metasubjective educational results. The results of the differences significance analysis between the selective means of teachers' educational results and the necessary level of their achievement at the level of significance $\mathrm{p}<0,05$ are presented in table 1. 
Table 1 - Teachers, who achieve high educational results

\begin{tabular}{|c|c|c|c|}
\hline Educational result & Sampling (N) & $\begin{array}{c}\text { The number of teachers, who achieve } \\
\text { high educational results (T) }\end{array}$ & $\begin{array}{c}\text { Part of T from } \\
\mathrm{N}\end{array}$ \\
\hline Personal & 84 & 25 & $29,8 \%$ \\
\hline Metasubjective & 84 & 19 & $22,6 \%$ \\
\hline
\end{tabular}

We studied the interconnection between the evaluation criteria of professional activity effectiveness by means of correlation analysis. The results of the interconnection analysis between the degree of personal and metasubjective educational results achievement show strong direct correlation connection in terms of correlation coefficient $\mathrm{R}=0,73$ at the significance level $\mathrm{p}<0,05$.
The results of correlational analysis between the mean values of the personal and metasubjective results achievement degree, according to FSES of MGE, and the degree of labor actions realization, according to the professional standard "Teacher", at the level of significance $\mathrm{p}<0,05$, are presented in table 2.

Table 2 - Interconnection between the groups of education quality criteria

\begin{tabular}{|c|c|c|c|c|c|}
\hline \multirow{2}{*}{ FSES } & \multirow{4}{|c|}{ Labor activities } \\
\hline \multirow{2}{*}{$\begin{array}{c}\text { Educational } \\
\text { results }\end{array}$} & Personal & Teaching & Upbringing & Development & $\begin{array}{c}\text { Programs } \\
\text { realization }\end{array}$ \\
\cline { 3 - 6 } & Metasubjective & 0,293 & 0,565 & 0,430 & 0,345 \\
\hline
\end{tabular}

We revealed moderate direct correlational connection between personal educational results and upbringing labor actions. Other connections are weak or are absent at all, however, there are connections between the separate evaluation criteria.

During further study of interconnection between the components of estimating the effectiveness of a teacher's professional activity we organized correlation analysis of the definite evaluation criteria of effectiveness at the significance level $\mathrm{p}<0,01$. Most received correlation connections are direct and weak, however, there are moderate connections and one weak negative correlation connection.

We should mention weak negative correlation connection between «M.3» и «D.5». It proves that during the direct help concerning students, they achieve less results concerning: the ability to correlate own actions with the planned results, realize control over own activity during the results achievement, define the ways of actions in accordance with the changing situation. Thus, we can say that direct help realization can have excessive character.

As we revealed insufficient degree of educational results achievement by teachers according to FSES of MGE, it is necessary to realize further work in the sphere of quality improvement of subjective activity organization among senior teen-agers at school. Such situation could be caused by the fact that teachers independently interpret or sometimes don't understand general formulations of the standard. Thus, we think that it is necessary to realize specification of the definitions of FSES demands together with the demands claimed on labor actions in accordance with professional standard of a teacher in order to create theoretical base not only for monitoring instruments creation, but also for the opportunity to organize some events directed toward problem zones evasion during the necessary level of educational results achievement. These events can be at the level of educational organization and in the form of qualification improvement courses.

\section{CONCLUSION}

As a result of creating and testing the 
methodology of a teacher's professional activity effectiveness estimation on the basis of several secondary schools we revealed the following:

- educational results according to FSES of MGE are not achieved at a sufficient degree, especially in the sphere of regulative universal educational actions formation and development;

- teachers' labor actions are not sufficiently realized in accordance with professional standard of a teacher in the sphere of special language programs use, the programs of language culture improvement and the skills of multicultural communication development; cooperative (with students) use of foreign sources of information, instruments of translation and pronunciation;

- teachers independently interpret or sometimes don't understand general formulations of the standard. It can cause the problems during the necessary level of educational results achievement;

- there is a strong direct correlation between personal and metasubjective educational results. There are usually either direct and weak, or no connections between the degree of educational results achievement according to FSES of MGE and the degree of labor actions realization according to professional standard of a teacher;

- it is necessary to specify general definitions of educational standards demands with close connection in order to create theoretical base for monitoring instruments creation and for the opportunity to organize some events directed toward problem zones evasion during a teacher's professional activity organization.

\section{REFERENCES}

1. Averkin V.N. Attestation: a teacher's activity results estimation. Narodnoe obrazovanie. 2012; 6: 107-117 [In Russ.].

2. Bryzgalina E.V. About the evaluation criteria of a teacher's pedagogical activity in terms of education quality control. Vestnik Moskovskogo universiteta. Seriya 7. Filosofiya. 2012; 6: 45-60 [In Russ.].

3. Nazarova S.I. Expertise of pedagogical education quality on the basis of professional standard. Chelovek I obrazovanie. 2015; 1(42): 129133 [In Russ.].

4. Rykhlova N. A teacher's professional activity monitoring. Shkol'noe planirovanie: zhurnal dlya shkol'nyh administratorov. 2013; 5: 39-58 [In Russ.].

5. Sedov S. A. The question of a teacher's professional activity effectiveness increase. Standarty I monitoring v obrazovanii. 2013; 1(88): 24-29 [In Russ.].

6. Shadrikov V.D., Kuznetsova I.V. Expert appraisal of a teacher's pedagogical activity. Spravochnik zamestitelya direktora shkoly. 2012; 11: 70-92 [In Russ.].

7. About federal state standard of general education adoption and introduction: order of the Ministry of Education and Science of Russia 17.12.2010 N 1897. Vestnik obrazovaniya. 2011; 4: 10-77 [In Russ.].

8. About professional standard "Teacher" adoption (pedagogical activity in the sphere of preschool, primary, general, secondary education) (educator, teacher)»: Order of the Ministry of Labor of Russia 18.10.2013 № 544H. Rossijskaya gazeta. 2013. URL: https://rg.ru/2013/12/18/pedagogdok.html [In Russ.].

9. Bauman A.E. Physical activity and exercise programs. Physical activity and health. 2007: 319-334.

10. Biddle S.J.H., Atkin A., Cavill N., Foster C. Correlates of physical activity in youth: A review of quantitative systematic reviews. International Review of Sport and Exercise Psychology. 2011; 4(1): 25-49.

11. Blair S.N. Physical inactivity: The biggest public health problem of the $21^{\text {st }}$ century. British Journal of Sports Medicine. 2009; 43(1): 1-2.

12. Brehm W., Wagner P., Sygusch R., Hahn U., Janke A. Health Promotion by means of Health Sport. A framework and a controlled intervention study with sedentary adults. Scandinavian Journal of Medicine and Science in Sports. 2005; 15(1): 1320.

\section{Submitted: 20.02.2020}

\section{Author's information:}

Artem F. Filipov - Post-Graduate, Yelabuga Institute (branch) of Kazan (Volga) Federal University, 42360o, Russia, Yelabuga, Kazanskaya str., House 89, e-mail: filipovartemf@gmail.com

Raziya F. Akhtarieva - Candidte of Pedagogics, Associate Professor, Yelabuga Institute (branch) of Kazan (Volga) Federal University, 4236oo, Russia, Yelabuga, Kazanskaya str., House 89, e-mail: raziya-a@yandex.ru 